\title{
Isolation of Two Homologous Triterpenes with Antimalarial Activities from the Leaf Extract of Combretum Zenkeri
}

\author{
Wande Oluyemi ${ }^{1,2}$, Babatunde Samue ${ }^{1 *}$, Kahlig Hans-Peter ${ }^{3}$, Taramelli Donatella ${ }^{4}$, \\ Krenn Liselotte ${ }^{2}$ \\ 1 University Of Ibadan, Pharmaceutical Chemistry Department, Ibadan/Oyo, Nigeria. \\ 2 University of Vienna, Department of Pharmacognosy, Althanstrasse, Vienna, Austria. \\ 3 University of Vienna, Department of Organic Chemistry, WahringerStrasse, Vienna, Austria. \\ 4 Universitàdegli Studi di Milano, Dipartimento di Scienze Farmacologiche, Milano, Milan, Italy.
}

\begin{abstract}
Combretum genus (Combretaceae) is used locally in the treatment of various diseases including malaria. Current study aimed to investigate the antiplasmodial activities of methanol extract of $C$. zenkeri in Plasmodium falciparum chloroquine sensitive (D10) and resistant (W2) strains and identify the bioactive principles. Repeated chromatographic separation was carried out on the chloroform fraction to afford the isolation of bioactive compounds which was characterized by application of spectroscopic techniques (ESI-MS, HR-ESIMS, 1D and 2D NMR). Antiplasmodial activities of chloroform fraction (D10; $\mathrm{IC}_{50}=12.57 \pm 1.57 \mu \mathrm{g} / \mathrm{mL}$ and $\mathrm{W} 2 ; \mathrm{IC}_{50}=$ $12.14 \pm 0.95 \mu \mathrm{g} / \mathrm{mL}$ ) showed more activity than the $\mathrm{n}$-butanol fraction (D10; $\mathrm{IC}_{50}=$ $61.98 \pm 3.25 \mu \mathrm{g} / \mathrm{mL}$ and $\mathrm{W}_{2} ; \mathrm{IC}_{50}=61.26 \pm 8.64 \mu \mathrm{g} / \mathrm{mL}$ ). Phytochemical investigation of the extract afforded isolation of two triterpenes with antimalarial activities. This paper identified for the first time the antimalarial principles in C. zenkeri as ursolic and oleanolic acids; which justified the local use of the plant in the treatment of malaria.
\end{abstract}

Keywords: C. zenkeri, antimalarial, bioguided isolation, triterpenes, Plasmodium falciparum.

*Corresponding Author: Babatunde Samuel, e-mail: tundebsamuel@gmail.com Wande Oluyemi ORCID Number: 0000-0003-3646-2488

Babatunde B. Samuel ORCID Number: 0000-0002-1834-9548

Kahlig Hans-Peter ORCID Number: 0000-0002-9526-4396

Taramelli Donatella ORCID Number: 0000-0001-5108-4492

Krenn Liselotte ORCID Number: 0000-0002-3898-6501

(Received 04 February 2019, accepted 24 March 2019) 


\section{INTRODUCTION}

Infectious diseases, among which is malaria, are the serious problem and cause of morbidity and mortality worldwide, particularly in the developing countries. This accounts for approximately 50\% of all deaths where access to health care is inadequate. ${ }^{1}$ Medicinal plants as the backbone of traditional medicine have over the years been subjected to serious pharmacological investigations with a view to discovering new bioactive molecules. ${ }^{2,3}$ Combretum is the largest genus of the Combretaceae family with about 370 species. ${ }^{4}$ Several species of Combretum are used in traditional medicine for treating various kinds of diseases by many communities across Africa. ${ }^{5}$ Phytochemical studies of a number of Combretum species have led to the isolation of triterpenoids with different pharmacological actions such as antimicrobial, anti-inflammatory anticancer and many others. ${ }^{6-8}$ Terpenoids, glycosides and acidic compounds were also identified as possible antimalarial agents in medicinal plants. ${ }^{9}$ Combretum zenkeri is a widely distributed climbing shrub used in tropical West Africa from Guinea to Southern Nigeria and Cameroon. The decoction preparation of the leaves of this plant is used as purgative, the twig is chewed by Ivory Coast women to relieve menstrual pain, treating intestinal worms and malaria treatment. ${ }^{10}$ In Western Nigeria, Combretum zenkeri leaves are used in the treatment of inflammatory diseases like rheumatoid-arthritis, and the roots used frequently in recipes for managing cancer. ${ }^{11,12}$ In previous studies, several pharmacological investigations for Combretum zenkeri such as nephro-protective effect, ${ }^{13}$ hepatoprotective effect, ${ }^{14}$ anti-oxidative activity and neuro-protective effect $^{15}$ and cytotoxic activity ${ }^{12}$ have been validated. In our more recent study, preliminary screening of 10 Combretaceae species showed that Combretum zenkeri possessed antimalarial activity. ${ }^{16}$ All these pharmacological effects show Combretum zenkeri as a promising and important phyto-agent in the search of bioactive compounds for the treatment of diseases. Until now, to the best of our knowledge, no bioactive constituent is reported to have been isolated from Combretum zenkeri, which prompted us to investigate its active constituents. Current study focus on the investigation of the antimalarial potential of $C$. zenkeri methanol extract and fractions which led to the isolation of two related triterpenes: ursolic acid (1) and oleanolic acid (2). This is the first time any bioactive principle is reported to have been identified from $C$. zenkeri.

\section{METHODOLOGY}

\section{General experimental methods}

1D and 2D Nuclear Magnetic Resonance (NMR) data were performed by using a Brucker $500 \mathrm{MHz}$ NMR spectrometer. The samples were measured at $298 \mathrm{~K}$ 
in fully deuterated methanol. The resonance frequency for ${ }^{1} \mathrm{H}$ and ${ }^{13} \mathrm{C}$ NMR was 700.40 MHz. Standard 1D and gradient-enhanced 2D experiments, such as, DEPT, COSY, TOCSY, NOESY, HSQC and HMBC were used. Electrospray ionization mass-spec (ESI-MS) and high-resolution mass spectrometric analyses were performed on a maxis mass spectrometer. The sum formulas of the ions were determined using Brucker Compass Data Analysis 4.1. Flash chromatography was performed on an InterchimpuriFlash 4250 system, equipped with an evaporative light scattering detector (ELSD), a photodiode array (PDA), and a fraction collector controlled by Interchim software. PuriFlash column 30 silica HG (120 g, 20 bar) served as stationary phase. The fractions obtained from all chromatographic steps were analyzed by TLC (mobile phase: $\mathrm{CH}_{3} \mathrm{Cl}$ / $\mathrm{MeOH}$, 95:5 or 97:3 depending on the polarity of all the fractions; stationary phase: Merck silica gel $60 \mathrm{~F}_{254}$, detected after derivatization with anisaldehyde $/ \mathrm{H}_{2} \mathrm{SO}_{4}$ spray reagent under visible light, $\mathrm{UV}_{254}$ and $\mathrm{UV}_{366^{\circ}}$.

\section{Plant material}

Fresh leaves of Combretum zenkeri was collected in March 2017 from the Botanical Garden of the University of Ibadan. The plant was identified by Mr. Owolabi, the curator of the Botanical Garden. The authentication was done, and the Voucher specimen was deposited at Forestry Research Institute of Nigeria (FRIN), Ibadan and the Voucher number obtained as FHI/110277.

\section{Plant extraction and isolation}

The air-dried and ground leaf of $C$. zenkeri (500 g) was extracted with methanol using soxhlet apparatus. The extract was filtered and evaporated to dryness using rotary evaporator and afterwards placed inside a desicator to remove residual solvent. Liquid-liquid partitioning was performed on the extract to give three different fractions (chloroform, n-butanol and aqueous). The dried methanol extract (10 g) was successively partitioned between $\mathrm{CHCl}_{3}$ and $\mathrm{H}_{2} \mathrm{O}$ and n$\mathrm{BuOH}$ and $\mathrm{H}_{2} \mathrm{O}$. The different fractions obtained were also dried on Buchi rotary evaporator at $40{ }^{\circ} \mathrm{C}$ to yield $700 \mathrm{mg} \mathrm{CHCl}_{3}$ fraction, $2.8 \mathrm{~g} \mathrm{n}-\mathrm{BuOH}$ fraction and $5.6 \mathrm{~g}$ water fraction. The $\mathrm{CHCl}_{3}$ fraction was then selected for further phytochemical investigation according to its appropriate antiplasmodial properties (the lowest $\mathrm{IC}_{50}$ ). To afford the major bioactive compound(s) of the plant, the $\mathrm{CHCl}_{3}$ fraction (600 mg) was further sub-fractionated by silica column (PuriFlash column 30 silica $\mathrm{HP} 40 \mathrm{G} 20$ bar) flash $\mathrm{CC}$ with a $\mathrm{CHCl}_{3} / \mathrm{MeOH} / \mathrm{H}_{2} \mathrm{O}$ gradient as mobile phase (36.54 mins 98\%:2\%:0\%; 36.94 mins 90\%:9\%:1\%; 36.94 mins 80\%:17\%:3\%; 36.94 mins 70\%:25\%:5\%; 18.94 mins 60\%:35\%:5\%) to yield 301 fractions which were later pooled according to the similarities in their TLC profile to give 9 fractions (FCZ1 to FCZ9). The fractions were concentrated to 
dryness under reduced pressure with Buchi rotary evaporator at $40^{\circ} \mathrm{C}$. FCZ2 (90 $\mathrm{mg}$ ) was investigated further by means of chromatographic separation on a silica glass column (1cm x 60cm; $250 \mathrm{~mL}$ column vol.) filled with silica gel 60 (70-230 mesh) (Merck) and separated by isocratic elution with mixture of $\mathrm{CHCl}_{3} / \mathrm{MeOH} /$ $\mathrm{H}_{2} \mathrm{O} 95+1.5+0.1$. The flow rate was set at $2 \mathrm{~mL} / 30$ minutes on electronic automatic fraction collector. This produced 21 fractions (F1-F21). From the TLC profiles, F12-F15 as a result of their similarities in TLC pattern afforded compound CZ-A (5 mg), a white amorphous powder; a mixture of two isomers which could not be separated by chromatography.

\section{Antiplasmodial test of extract and fractions}

\section{In vitro maintenance of Plasmodium falciparum strains}

Two different strains of $P$. falciparum, W2 (chloroquine-resistant) and D1o (chloroquine-sensitive), were used for the chemosensitivity tests. Both strains were cultured according to the method described by Trager and Jensen with slight modifications $\mathbf{s}^{17,18}$. The parasites were cultured in human type A-positive erythrocytes at $5 \%$ hematocrit at $37^{\circ} \mathrm{C}$ in a standard gas mixture consisting of $1 \% \mathrm{O}_{2}, 5 \% \mathrm{CO}_{2}, 94 \%$ $\mathrm{N}_{2}$. The medium was RPMI-1640 (EuroClone, Celbio) with the addition of $1 \% \mathrm{Al}-$ buMax (lipid-rich bovine serum albumin) (Invitrogen, Milan, Italy), 0.o1\% hypoxantine (Sigma, Italy), 20mM Hepes (EuroClone, Celbio) and 2mM L-glutamine (EuroClone, Celbio). For routine parasite growth, the parasitemia was maintained within $1 \%$ and $5 \%$, and evaluated in Giemsa colored smears, as the number of infected RBC with respect to the total number of erythrocytes counted.

\section{Drug sensitivity assay}

For the drug sensitivity assay, a colorimetric method was used based on the detection of parasite $\mathrm{LDH}^{19}$. Parasite growth was determined by measuring the activity of the parasite lactate dehydrogenase (pLDH), according to a modified version of Makler's method ${ }^{19}$. Antimalarial activity was determined and expressed as the $50 \%$ inhibitory concentrations $\left(\mathrm{IC}_{50}\right.$, concentration of drug required to inhibit 50\% parasite growth). Each $\mathrm{IC}_{50}$ value is the mean \pm standard deviation of at least three separate experiments performed in duplicate.

\section{RESULTS AND DISCUSSION}

The methanol extract of the leaves of $C$. zenkeri was concentrated under a reduced pressure and then partitioned successively with $\mathrm{CHCl}_{3}, \mathrm{n}-\mathrm{BuOH}$ and $\mathrm{H}_{2} \mathrm{O}$. The $\mathrm{CHCl}_{3}$ soluble fraction, according to its appropriate antiplasmodial activity

(lowest $\mathrm{IC}_{50}$ ), was selected for silica flash CC followed by a glass column separation over a silica gel to afford compound CZ-A (5 mg). The structure of CZ-A 
was unambiguously determined and elucidated by spectroscopic experiments including $1 \mathrm{D}\left({ }^{1} \mathrm{H}\right.$ and ${ }^{13} \mathrm{C}$ NMR), 2D NMR (COSY, TOCSY, NOESY, HSQC and HMBC), ESI-MS and HR-ESIMS, and by comparison with reported data in related literature. Compound CZ-A was found to be an isomeric mixture (1:0.4) as revealed from the spectroscopic information. The MS gave a molecular ion peak at $\mathrm{m} / \mathrm{z} 456(\mathrm{M}-\mathrm{H})$ relating to $\mathrm{C}_{30} \mathrm{H}_{48} \mathrm{O}_{3}$. The isomers were identified as ursolic acid (3ß-hydroxyurs-12-en-28-oic acid) (1) ${ }^{20}$ and oleanolic acid ( $3 \beta$-hydroxyolean-12en-28-oic acid) (2) ${ }^{21}$ (figure 1). This study is one among others carried out on species of Combretum genus where compounds were isolated as mixtures of two isomers. From C. nelsonii, arjunolic acid with asiatic acid as mixtures of two isomers were isolated. ${ }^{22}$ Likewise in another study, ursolic acid with oleanolic acid as isomeric mixture, and maslinic acid with $2 \alpha, 3 \beta$-dihydroxyurs-12-en-28-oic acid as isomeric mixture were isolated from $C$. zeyheri. ${ }^{23}$ Compound $\mathbf{2}$ showed a signal pattern very similar to those of $\mathbf{1}$ in both ${ }^{1} \mathrm{H}$ and ${ }^{13} \mathrm{C}$ experiments (Table 1), but with the main difference noted in the DEPT experiment, where $\mathbf{1}$ and $\mathbf{2}$ possessed seven and eight quaternary carbon atom (C), seven and six methine group $(\mathrm{CH})$, nine and ten methylene group $\left(\mathrm{CH}_{2}\right)$, respectively, with seven methyl groups for each compound. The chemical shifts of olefinic carbons revealed on ${ }^{13} \mathrm{C}$ NMR signals help to unambiguously identify compounds $\mathbf{1}$ and $\mathbf{2}$. Previous report has confirmed that for the olean-12-ene type, the chemical shifts of the double bond $\mathrm{C}_{12}$ and $\mathrm{C}_{13}$ are around 122.0 and 144.0, respectively, while those of its isomer urs-12-ene are around 125.0 and 139.0, respectively, for the same carbons. ${ }^{24}$ This characteristic chemical sifts of oleanane and ursane triterpenes are consistent with ${ }^{13} \mathrm{C}$ NMR signals generated in this study; help to establish the difference between compound 1 and 2 and elucidate their structures in the mixture.

$3 \beta$-hydroxyurs-12-en-28-oic acid and its isomer, $3 \beta$-hydroxyolean-12-en-28-oic acid are reported to have been isolated from Combretum zenkeri for the first time in this study.

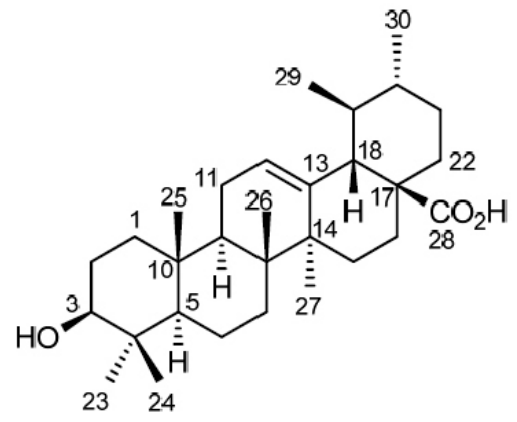

1

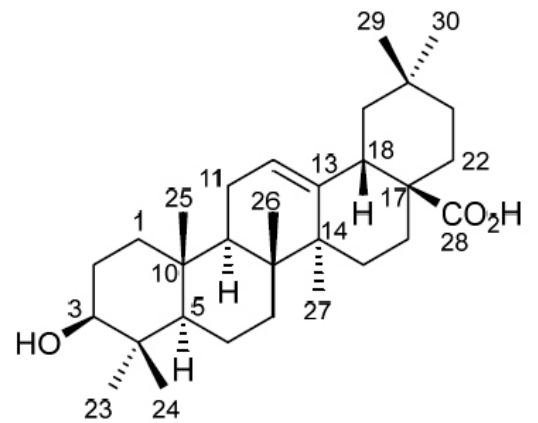

2

Figure 1. Compound 1 and 2, isomeric mixture identified in CZ-A isolated from C. zenkeri 
Table 1. ${ }^{1} \mathrm{H}$ and ${ }^{13} \mathrm{C}$ NMR $(700 \mathrm{MHz})$ data generated for compound 1 and 2 in $\mathrm{CD}_{3} \mathrm{OD}$

\begin{tabular}{|c|c|c|c|c|}
\hline \multirow[b]{3}{*}{1} & \multicolumn{2}{|l|}{1} & \multicolumn{2}{|c|}{2} \\
\hline & \multicolumn{2}{|c|}{$\delta_{H} m(J$ in $\mathrm{Hz}) \delta_{c}$} & \multicolumn{2}{|c|}{$\delta_{H} m(J$ in $\mathrm{Hz}) \delta_{c}$} \\
\hline & $\begin{array}{r}1.67 \mathrm{~m} \\
1.01\end{array}$ & 39.99 & $\begin{array}{l}1.63 \mathrm{~m} \\
0.99 \mathrm{~m}\end{array}$ & 39.83 \\
\hline 2 & $\begin{array}{r}1.63 \mathrm{~m} \\
1.56\end{array}$ & 27.90 & $\begin{array}{r}1.63 \mathrm{~m} \\
1.56\end{array}$ & 27.87 \\
\hline 3 & $3.15 \mathrm{dd}(11.7,4.6)$ & 79.70 & $3.15 \mathrm{~m}$ & 79.71 \\
\hline 4 & - & 39.84 & - & 40.55 \\
\hline 5 & $0.75 \mathrm{dd}(11.8,1.6)$ & 56.74 & $0.76 \mathrm{~m}$ & 56.76 \\
\hline 6 & $\begin{array}{l}1.56 \mathrm{~m} \\
1.42 \mathrm{~m}\end{array}$ & 19.47 & $\begin{array}{l}1.56 \mathrm{~m} \\
1.42 \mathrm{~m}\end{array}$ & 19.50 \\
\hline 7 & $\begin{array}{l}1.55 \mathrm{~m} \\
1.34 \mathrm{~m}\end{array}$ & 34.33 & $\begin{array}{l}1.51 \mathrm{~m} \\
1.32 \mathrm{~m}\end{array}$ & 34.02 \\
\hline 8 & - & 40.78 & - & 40.78 \\
\hline 9 & $1.55 \mathrm{~m}$ & 49.06 & $1.59 \mathrm{~m}$ & 49.10 \\
\hline 10 & - & 38.10 & - & 38.17 \\
\hline 11 & $1.93 \mathrm{~m}$ & 24.36 & $1.93 \mathrm{~m}$ & 24.52 \\
\hline 12 & $5.23 \mathrm{t}(3.7)$ & 126.88 & $5.24 \mathrm{t}(3.7)$ & 123.62 \\
\hline 13 & - & 139.66 & - & 145.25 \\
\hline 14 & - & 43.25 & - & 42.89 \\
\hline 15 & $\begin{array}{l}1.93 \mathrm{~m} \\
1.09 \mathrm{~m}\end{array}$ & 29.22 & $\begin{array}{l}1.78 \mathrm{~m} \\
1.08 \mathrm{~m}\end{array}$ & 28.85 \\
\hline 16 & $\begin{array}{r}2.04 \mathrm{~m} \\
1.65\end{array}$ & 25.33 & $\begin{array}{r}1.74 \mathrm{~m} \\
1.26\end{array}$ & 24.06 \\
\hline 17 & - & 49.10 & - & 47.67 \\
\hline 18 & $2.20 \mathrm{dd}(11.5,1.0)$ & 54.38 & $2.85 \mathrm{~m}$ & 42.75 \\
\hline 19 & $1.38 \mathrm{~m}$ & 40.44 & $\begin{array}{l}1.69 \mathrm{~m} \\
1.12 \mathrm{~m}\end{array}$ & 47.27 \\
\hline 20 & $0.99 \mathrm{~m}$ & 40.42 & - & 31.62 \\
\hline 21 & $\begin{array}{l}1.50 \mathrm{~m} \\
1.35 \mathrm{~m}\end{array}$ & 31.79 & $\begin{array}{l}1.39 \mathrm{~m} \\
1.20 \mathrm{~m}\end{array}$ & 34.91 \\
\hline 22 & $\begin{array}{l}1.70 \mathrm{~m} \\
1.63 \mathrm{~m}\end{array}$ & 38.13 & $\begin{array}{l}1.74 \mathrm{~m} \\
1.54 \mathrm{~m}\end{array}$ & 33.84 \\
\hline 23 & $0.98 \mathrm{~s}$ & 28.76 & $0.97 \mathrm{~s}$ & 28.73 \\
\hline 24 & $0.78 \mathrm{~s}$ & 16.37 & $0.78 \mathrm{~s}$ & 16.31 \\
\hline 25 & $0.96 \mathrm{~d}(0.6)$ & 16.02 & $0.95 d(0.6)$ & 15.88 \\
\hline 26 & $0.85 \mathrm{~s}$ & 17.81 & $0.82 \mathrm{~s}$ & 17.73 \\
\hline 27 & $1.12 \mathrm{~d}(0.7)$ & 24.08 & $1.16 \mathrm{~d}(0.7)$ & 26.38 \\
\hline 28 & - & 181.74 & - & 181.96 \\
\hline 29 & $0.88 \mathrm{~d}(6.5)$ & 17.64 & $0.94 \mathrm{~s}$ & 23.98 \\
\hline 30 & $0.96 \mathrm{~m}$ & 21.57 & $0.91 \mathrm{~s}$ & 33.57 \\
\hline
\end{tabular}


Table 2. Antiplasmodial activity of $\mathrm{C}$. zenkeri methanol extract and fraction in P. falciparum chloroquine sensitive (D10) and resistant (W2) strains.

\begin{tabular}{|c|c|c|}
\hline & D10 $\left(I C_{50} \mu \mathrm{g} / \mathrm{mL}\right)^{\mathrm{a}}$ & W2 $\left(\mathrm{IC}_{50} \mu \mathrm{g} / \mathrm{mL}\right)^{\mathrm{a}}$ \\
\hline C. zenkeri $\mathrm{MeOH}$ extract & $68.98 \pm 1.00^{c}$ & $69.68 \pm 3.09^{d}$ \\
\hline $\mathrm{CHCl}_{3}$ fraction & $12.57 \pm 1.57$ & $12.14 \pm 0.95$ \\
\hline n-BuOH fraction & $61.98 \pm 3.25^{b}$ & $61.26 \pm 8.64^{b}$ \\
\hline Chloroquine (ng/mL) & $13.1 \pm 2.4$ & $217.0 \pm 28.0$ \\
\hline
\end{tabular}

${ }^{a}$ Data are the mean $\pm S D$ of three different experiments in duplicate

bThe activity of $\mathrm{CHCl}_{3}$ fraction is significantly $(\mathrm{P}<0.05)$ higher compared with $\mathrm{n}-\mathrm{BuOH}$

cThe activity of $\mathrm{CHCl}_{3}$ fraction is significantly $(\mathrm{P}<0.001)$ higher compared with $\mathrm{C}$. zenkeri $\mathrm{MeOH}$ extract

dThe activity of $\mathrm{CHCl}_{3}$ fraction is significantly $(\mathrm{P}<0.01)$ higher compared with $\mathrm{C}$. zenkeri $\mathrm{MeOH}$ extract

Antiplasmodial test was carried out in P. falciparum chloroquine sensitive (D10) and resistant (W2) strains to check the activities of $C$. zenkeri extract and fractions obtained from solvent-solvent partitioning and the results are summarized in Table 2. The water fraction was not tested due to its high tannin content which interferes with the actual antimalarial activity. The $C$. zenkeri methanol extract showed good antiplasmodial activities $\left(\mathrm{IC}_{50}=68.98 \pm 1.00 \mu \mathrm{g} /\right.$ $\mathrm{mL})$ and $\left(\mathrm{IC}_{50}=69.68 \pm 3.09 \mu \mathrm{g} / \mathrm{mL}\right)$ for both chloroquine sensitive D10 and resistant W2 strains respectively. In this experiment, the chloroform fraction showed promising activities $\left(\mathrm{IC}_{50}=12.57 \pm 1.57 \mu \mathrm{g} / \mathrm{mL}\right)$ and $\left(\mathrm{IC}_{50}=12.14 \pm 0.95\right.$ $\mu \mathrm{g} / \mathrm{mL}$ ) more than 5 -folds active than the crude extract for both sensitive D10 and resistant W2 strains respectively. This observation is indicative of the fact that the major compound(s) responsible for the antimalarial activities in the $C$. zenkeri methanol extract situate in the chloroform soluble fraction. The antimalarial activity of the extract would be partly or majorly due to the presence of ursolic acid because this compound isolated from Morinda lucida was shown to exhibit excellent in vitro and in vivo antimalarial activities. ${ }^{25}$ Interesting in vitro antiplasmodial activities $\left(\mathrm{IC}_{50}=3.1 \pm 1.3 \mu \mathrm{g} / \mathrm{mL}\right.$ ), about 5 -folds more active than oleanolic acid $\left(\mathrm{IC}_{50}=15.2 \pm 3.4 \mu \mathrm{g} / \mathrm{mL}\right.$ ) against a chloroquine sensitive $P$. falciparum strain was reported. ${ }^{25}$ Likewise for in vivo test in the same study, ursolic acid produced $97.7 \%$ chemosuppression of parasitemia in mice infected with Plasmodium berghei berghei, greater reduction in parasitemia compared to oleanolic acid 37.5\%. Although effort is currently ongoing to isolate and purify other compounds from the said chloroform fraction, as there may be other principles with related activities from this extract. In this study the activity test of their mixture (ursolic/oleanolic acids) was not possible as a result of insufficient amount isolated. Although, in a few cases the activity of their mixture in other pharmacological activities has shown to be greater than 
that of the single compounds, ${ }^{26,27}$ and extensive data about the synergistic antimalarial activity of these two isomers is lacking. Some studies have recently described ursolic acid as a pentacyclic triterpenoid with a wide spectrum of pharmacological activities such as protective effect on lungs, kidneys, liver and brain, anti-inflammatory properties, anabolic effect on skeletal muscles, antiosteoporosis, antimicrobial effect against numerous strains of bacteria, anti HIV and HCV viruses and antimalarial among others ${ }^{28,29,30}$ Consequently, it is plausible to suggest that the presence of ursolic acid in C. zenkeri contribute hugely to the different pharmacological actions ${ }^{13-16}$ exerted by the plant. However, it is important to widely explore $C$. zenkeri for its other bioactive constituents which may be useful lead compounds or scaffolds necessary for their synthesis for many other pharmacological investigations important. An analogue of ursolic acid, N-\{3-[4-(3-aminopropyl)piperazinyl]propyl\}-3-Oacetylursolamide, which reported showed better antimalarial activity (175 nM) than the aglycone. ${ }^{31}$ This report showed that the ursolic acid derivative which showed to be non-toxic demonstrated a new potent antimalarial prototype that disrupts plasmodium calcium homeostasis.

Ongoing studies in our laboratory is targeted at creating several derivatives of ursolic acid with a view to obtaining more potent and less toxic antimalarial agents. These studies further highlight the need for further investigation of unexplored Combretum species of Africa, particularly Combretum zenkeri.

The Combretaceae family is significant in the search for bioactive compounds useful in the treatment of malaria. This study showed the antimalarial potential of Combretum zenkeri and justified its use in traditional medicine. Triterpenoids have contributed largely to the antimalarial activities of several medicinal plants.

Two closely related triterpenes, ursolic acid and oleanolic acid were isolated as known antimalarial principles from Combretum zenkeri. Ursolic acid may contribute largely to the antimalarial effect of the extract. Further studies are ongoing on Combretum zenkeri to isolate more possible compounds which could possess antimalarial or other pharmacological activities.

\section{ACKNOWLEDGEMENTS}

The first author appreciates The Austrian Agency for International Cooperation in Education, Science and Research (OeAD-GmbH)- Ernst Mach for the scholarship awarded to complete this work in University of Vienna, Austria. 


\section{REFERENCES}

1. Mosaffa-Jahromi, M.; Lankarani, K.B.; Pasala, M.; Afsharypuor, S.; Tamaddon, A.M. Efficacy and safety of enteric coated capsules of anise oil to treat irritable bowel syndrome. $J$. Ethnopharmacol. 2016, 194, 937-946.

2. Samuel, B.; Oluyemi, W. M.; Abiodun, O. Bio-guided investigation of the antimalarial activities of Trema orientalis (L.) Blume leaves. Afr. J. Biotechnol. 2015, 14, 2966-2971.

3. Makhafola, T.J.; Samuel, B.B.; Elgorashi, E.E.; Eloff, J.N. Ochnaflavone and Ochnaflavone 7-O-methyl Ether: two Antibacterial Biflavonoids from Ochna pretoriensis (Ochnaceae). Nat. Prod. Commun. 2012, 7, 1601-1604.

4. McGaw, L.J.; Rabe, T.; Sparg, S.G.; Jäger, A.K.; Eloff, J.N.; Van Staden, J. An investigation on the biological activity of Combretum species. J. Ethnopharmacol. 2001, 75, 45-50.

5. Eloff, J.N.; Katerere, D.R.P.; McGaw, L.J. The biological activity and chemistry of the southern African Combretaceae. J. Ethnopharmacol. 2oo8, 119, 686-699.

6. Eloff, J.N. The antibacterial activity of 27 southern African members of the Combretaceae. S. Afr. J. Sci. 1999, 95, 148-152.

7. Angeh, J.E.; Huang, X.; Sattler, I.; Swan, G.E.; Dahse, H.; Hartl, A.; Eloff, J.N.

Antimicrobial and anti-inflammatory activity of four known and one new triterpenoid from Combretum imberbe (Combretaceae). J. Ethnopharmacol. 2007, 110, 56-60.

8. Pettit, G.R.; Singh, S.B.; Niven, M.L.; Schimdt, J.M. Cell growth inhibitory dihydrophenanthrene and phenanthrene constituents of the African tree Combretum caffrum. Can. J. Chem. 1988, 66, 406-413.

9. Dibua, U.M.; Okeke, C.C.; Ugwu, C.; Kenechukwu, F.C.; Okorie, A. In vivo antimalarial and cytotoxicity activity of ethanolic stem bark of Petersianthus macrocarpus and leaf of Astonia boonei in experimental mice model. Int. J. Curr. Microbiol. App. Sci. 2013, 2, 354-368.

10. Ujowundu, C.O.; Okafor, O.E.; Agha, N.C.; Nwaogu, L.A.; Igwe, K.O.; Igwe, C.U. Phytochemical and chemical composition of C. zenkeri leaves. J. Med. Plant Res. 2010, 4, 965-968.

11. Gbolade, A. A.; Ogbole, O. O.; Ajaiyeoba, E. O. Ethnobotanical Survey of Plants used in Treatment of Inflammatory Diseases in Ogun State of Nigeria. Euro. J. Sc. Res. 2010, 43, 183-191.

12. Sowemimo, A.; Van de Venter, M.; Baatjies, L.; Koekemoer, T. Cytotoxic activity of selected Nigerian plants. Afr. J. Trad. CAM. 2009, 6, 526-528.

13. Ogbonna, C.U.; Ujowundu, C.O.; Okwu, G.N.; Emejulu, A.A.; Alisi, C.S.; Igwe, K.O. Biochemical and histological evaluation of benzo[a]pyrene induced nephrotoxicity and therapeutic potentials of C. zenkeri leaf extract. Afr. J. Pharm. and Pharmacol. 2016, 10, 873-882.

14. Okwu, G.N.; Ogbonna, C.U.; Ujowundu, C.O.; Igwe, K.O.; Igwe, C.U.; Emejulu A.A. 2014. Protective effect of ethanol leaf extract of C. zenkeri on liver functions of Albino rats following benzo[a]pyrene exposure. Biol. Chem. Res. 2014, 16-25.

15. Ujowundu, C.O; Ogbonna, C.U.; Okwu, G.N.; Alisi, C.S. Free radicals scavenging and neuroprotective effects of ethanolic leaf extract of Combretumzenkeri. Annu. Res. Rev. Bio., 2015, 6, 133-141.

16. Oluyemi, M. W.; Samuel, B. B. In vitro screening of ten Combretaceae plants for antimalarial activities applying the inhibition of beta-hematin formation. Int. J. Biol. Chem. Sci. 2017, 11, 2971-2981. 
17. Trager, W.; Jensen, J. B. Human malaria parasites in continuous culture. Science, 1976, 193 , $673-675$.

18. Ilboudo, D.P.; Basilico, N.; Parapini, S.; Corbett, Y.; D’Alessandro, S.; Dell'Agli, M.; Coghi, P.; Karou, S.D.; Sawadogo, R.; Gnoula, C.; Simpore, J.; Nikiema, J.B.; Monti, D.; Bosisio, E.; Taramelli, D. Antiplasmodial and anti-inflammatory activities of Canthium henriquesianum (K. Schum), a plant used in traditional medicine in Burkina Faso. J. Ethnopharmacol. 2013, 148, 763-769.

19. Makler, M. T.; Ries, J. M.; Williams, J. A.; Bancroft, J. E.; Piper, R. C.; Gibbins, B. L.; Hinrichs, D. J. Parasite Lactate Dehydrogenase as an Assay for Plasmodium falciparum Drug Sensitivity. Am. J. Trop. Med. Hyg. 1993, 48, 739-741.

20. Venditti, A.; Lattanzi, C.; Ornano, L.; Maggi, F.; Sanna, C.; Ballero, M.; Alvinao, A.; Serafini, M.; Bianco, A. A new glucosidicphthalide from Helichrysum microphyllum sub sp. Tyrrhenicum from La Maddalena Island (Sardinia, Italy), Nat. Prod. Res., 2016, 30, 789-795.

21. Kipchakbaeva, A.K.; Eskalieva, B.K.; Burasheva, G.Sh.; Adikari, A.; Aisa, H.A.; Choudhary, M.I. Saponins from Climacoptera subcrassa. Chem. Nat. Compds, 2016, 52, 363-364.

22. Masoko, P.; Mdee, L.K.; Mampuru, L.J.; Eloff J.N. Biological activity of two related triterpenes isolated from Combretum nelsonii (Combretaceae) leaves. Nat. Prod. Res. 20o8, 22, 1074-1084.

23. Runyoro, D.K.B.; Srivastava, S.K.; Darokar, M.P.; Olipa, N.D.; Joseph, C.C.; Matee, M.I.N. Anticandidiasis agents from a Tanzanian plant, C. zeyheri. Med. Chem. Res. 2013, 22, 1258-1262.

24. Mahato, S.B.; Kundu, A.P. ${ }_{13}$ C NMR spectra of pentacyclic triterpenoids-a compilation and some salient features. Phytochemistry, 1994, 37, 1517-1575.

25. Cimanga, R.K.; Tona, G.L.; Mesia, G.K.; Kambu, O.K.; Bakana, D.P.; Kalenda, P.D.T.; Penge, A.O.; Muyembe, J.T.; Totte, J.; Pieters, L.; Vlietinck, A.J. Bioassay-guided isolation of triterpenoid acids from the leaves of Morinda lucida. Pharm Biol. 2006, 44, 677-681.

26. Bisio, O.A.; Schito, A.M.; Parricchi, A.; Mele, G.; Romussi, G.; Malafronte, N.; Oliva, P.; Tommasi, N. Antibacterial activity of constituents from Salvia buchananii Hedge (Lamiaceae). Phytochem. Lett. 2015, 14, 170-177.

27. Jimenez-Arellanes, A.; Luna-Herrera, J.; Cornejo-Garrido, J.; Lopez-Garcia, S.; CastroMussot, M.E.; Meckes-Fischer, M.; Mata-Espinosa, D.; Marquina, B.; Torres, J.; HernandezPando, R. Ursolic and oleanolic acids as antimicrobial and immunomodulatory compounds for tuberculosis treatment. BMC Complement. Altern. Med. 2013, 13, 258.

28. Wozniak, L.; Skapska, S.; Marszalek, K. Ursolic acid- A pentacyclic triterpenoid with a wide spectrum of pharmacological activities. Molecules, 2015, 2O, 20614-20641.

29. Awan, Z.I.; Habib-Ur-Rehman, Minhas, F.A.; Awan, A.A. Antiplasmodial activity of compounds isolated from Viburnum nervosum. Int. J. Pharm. Sci. Invent. 2013, 2, 19-24.

30. Jie Liu. Oleanolic acid and ursolic acid: Research perspectives. J. Ethnopharmacol. 2005, 100, 92-94.

31. Innocente, A.M.; Silva, G.N.S.; Cruz, L.N.; Moraes, M.S.; Nakabashi, M.; Sonnet, P.; Gosmann, G.; Garcia, C.R.S.; Gnoatto, S.C.B. Synthesis and antiplasmodial activity of betulinic acid and ursolic acid analogues. Molecules, 2012, 17, 12003-12014. 